\title{
Mengenal Geometri Melalui Permainan Lompat Geometri di Kelompok Bermain Miftahul Hidayah Demak
}

\author{
Siti Solichah, Marini, M. Sukiram, Maria Denok
}

Prodi Pendidikan Guru Pendidikan Anak Usia Dini, Fakultas Keguruan dan Ilmu Pendidikan, Universitas IVET, Indonesia

\section{Info Articles}

Sejarah Artikel:

Disubmit 6 April 2021

Direvisi 11 April 2021

Disetujui 3 Mei 2021

\section{Keywords:}

Games; geometry; jump rope; clidren

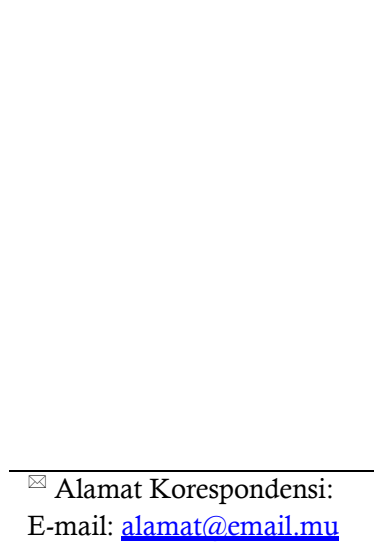

\begin{abstract}
Abstrak
Peningkatan kemampuan kognitif anak usia 3-4 tahun bergantung pada pembelajaran dan pembiasaan, cara mengajar di sekolah dan ragam alat pembelajaran yang digunakan juga sangat berpengaruh untuk keberhasilan peningkatan kognitif anak. Fakta yang tejadi di Kelompok Belajar Miftahul Hidayah Demak permasalahannya adalah kurangnya stimulasi perkembangan kognitif anak khususnya dalam mengenal bentuk geometri inilah yang di angkat pada penelitian ini. Maka metode PTK yang digunakan sebagai cara untuk mengurangi permasalahan yang ada. Subjek penelitian adalah 15 anak usia 3-4 tahun yang belajar di Kelompok Bermain Miftahul Hidayah Demak. Hasil penelitian ini menunjukkan bahwa upaya peningkatan kemampuan mengenal geometri mampu terstimulasi dengan baik dari proses belajar dengan menggunakan permainan lompat geometri. Hasil ini terlihat setelah proses PTK terlaksana mulai dari proses pra siklus, siklus I sampai siklus II.
\end{abstract}

\section{Abstract}

The increase in cognitive abilities of children aged 3-4 years depends on learning and habituation, who to teaching in schools and the variety of learning tools used are also very influential for the success of children's cognitive improvement. The fact that happened in the Miftahul Hidayah Demak Study Group, the problem is the lack of stimulation of children's cognitive development, especially in recognizing geometric shapes, which is adopted in this study. So the PTK method is used as a way to reduce existing problems. The research subjects were 15 children aged 3-4 years who studied in the Miftahul Hidayah Demak Play Group. The results of this study indicate that efforts to improve the ability to recognize geometry can be stimulated well from the learning process by using geometric jumping games. These results can be seen after the PTK process is carried out starting from the pre-cycle process, cycle I to cycle II.

p-ISSN XXXX-XXX e-ISSN XXXX-XXX 


\section{PENDAHULUAN}

Pendidikan Anak Usia Dini merupakan suatu upaya pembinaan yang ditujukan kepada anakanak sejak lahir hingga usia enam tahun yang dilakukan melalui pemberian rangsangan pendidikan untuk membantu pertumbuhan dan perkembangan jasmani dan rohani agar anak memiliki kesiapan dalam memasuki jenjang pendidikan lanjut. Pendidikan anak usia dini bahkan sampai saat ini bahkan masih menjadi sebuah kebutuhan penting bagi persiapan manusia yang unggul (Agustiningrum, 2020).

Anak usia dini berada pada tahap praoperasional di mana pada tahap ini merupakan tahap persiapan ke arah pengorganisasian pekerjaan yang konkret dan dapat berpikir intuitif (Triharso, 2013). Pada tahap ini anak sudah mengenal bentuk, dapat mempertimbangkan ukuran besar atau kecil, panjang atau pendek pada benda yang didasarkan pada pengalaman dan persepsi anak. Karena itulah, apabila guru menjelaskan materi diharapkan anak-anak mengenal hal-hal yang konkret berdasarkan pengalamannya.

Proses kegiatan belajar mengajar pada anak usia dini dilakukan dengan bermain atau permainan, supaya anak lebih minat dalam mengikuti kegiatan. Permainan merupakan alat untuk mengembangkan tingkat kreatifitas anak karena dengan adanya permainan anak akan menjadi lebih semangat atau anak lebih tertarik. Dengan metode bermain menjadikan anak lebih berpikir kritis untuk mendapatakan hasil yang lebih baik dan mampu memecahkan masalah yang akan dihadapi. Dalam sebuah permainan anak akan mencoba untuk melakukan permainan, karena rasa ingin tahu atau rasa penasaran anak terhadap permainan yang akan dilakukan sehingga anak akan tertarik untuk mencoba melakukan permainan tersebut dengan berbagai cara yang akan dilakukan (Slamet, 2005).

Kenyataan yang terjadi di KB Miftahul Hidayah kemampuan kognitif anak masih rendah, anak-anak masih kebingungan dalam menyebutkan bentuk segi empat, lingkaran, dan segitiga ( Novitasari, 2018). Rendahnya kemampuan mengenal bentuk geometri pada anak Kelompok Bermain Miftahul Hidayah disebabkan oleh beberapa penyebab yaitu, penggunaan media pembelajaran yang digunakan terbatas, guru hanya mengenalkan dua macam bentuk geometri saja yaitu bentuk segi empat dan lingkaran. Selain itu, guru hanya menggunakan media papan tulis dan gambar macam-macam bentuk geometri, akibatnya kemampuan anak dalam mengenal bentukbentuk geometri belum terkuasai dengan baik. Anak-anak masih kebingungan saat menyebutkan macam-macam bentuk geometri yaitu bentuk segi empat, segitiga, dan lingkaran.

Hasil observasi awal menunjukkan bahwa metode pembelajaran yang digunakan adalah ceramah, guru hanya bercerita di depan menerangkan gambar bentuk gemetri akibatnya saat kegiatan belajar mengajar berlangsung suasana kelas kurang kondusif, banyak anak yang bercerita dengan teman, dan ada yang bermain sendiri, sehingga proses kegiatan belajar mengajar kurang maksimal. Kegiatan pengenalan bentuk-bentuk geometri dengan permainan tidak pernah dilakukan. 
Selain itu guru hanya mengulang-ulang kegiatan pembelajarannya dengan mengerjakan lembar kerja / majalah tanpa diselingi dengan kegiatan bermain. Kondisi seperti inilah yang membuat anak kurang antusias saat melakukan kegiatan pembelajaran.

Mengajarkan pemahaman tentang geometri untuk anak usia dini merupakan hal penting, karena mengenal geometri adalah salah-satu pemahaman dasar tentang matematika dan kognitif. Dibutuhkan media pembelajaran yang baik dan mampu mengakomodir perkembangan dan kebutuhan anak, sebab dunia anak merupakan dunia bermain. Metode pembelajaran yang ada di $\mathrm{KB}$ seharusnya diarahkan dengan cara bermain sambil belajar yang dikemas dengan menarik, dalam mengembangkan kemampuan mengenalkan bentuk geometri pada anak-anak dapat dilakukan dengan berbagai hal (Murgiyati, 2020). Untuk memecahkan permasalahan, maka peneliti akan mempergunakan permainan lompat geometri untuk mengenalkan berbagai bentuk geometri pada anak-anak KB Miftahul Hidayah, dengan permainan ini penulis berharap dapat meningkatkan kognitif anak dengan lebih baik.

Rumusan masalah pada penelitian ini adalah: Permainan apa yang mampu menstimulasi perkembangan anak di Kelompok Bermain Miftahul Hidayah dalam mengenal bentuk geometri.

\section{METODE}

Penelitian yang dilakukan oleh penulis di Kelompok Bermain Miftahul Hidayah Desa Sidoharjo Kecamatan Guntur Kabupaten Demak ini, penulis mengambil jenis Penelitian Tindakan Kelas (PTK). Menurut Sugiyono (2013), penelitian tindakakan kelas atau PTK adalah salah satu jenis penelitian tindakan yang dilakukan oleh guru untuk meningkatkan kualitas pembelajaran dikelasnya melalui beberapa metode, pendekatan, penggunaan media, teknik evaluasi.

Beberapa langkah yang digunakan untuk mengurangi permasalahan dalam penelitian ini sehingga ditemukan jawaban yang tepat atas permasalahan yang terjadi. Langkah awal untuk memahami kondisi yang ada pada penelitian ini dilakukan proses prasiklus lalu dilanjutkan dengan pelaksanaan siklus I dan di sempurnakan dengan melaksanakan siklus II.

Proses pra siklus dilaksanakan untuk mengetahui kondisi awal perkembangan kognitif di Kelompok Bermain Miftahul Hidayah, cara mengajar guru dan alat permainan edukatif yang tersedia untuk mendukung proses belajar mengajar.

Siklus I dilaksanakan untuk menstimulasi perkembangan kognitif anak dengan menggunakan permainan lompat geometri yang disediakan oleh peneliti dan dilaksanakan dengan bantuan guru untuk meningkatkan kemampuan tersebut.

Siklus II dilaksanakan setelah evaluasi dari Siklus I dan mengoptimalkan hasil pembelajaran untuk meningkatkan kemampuan kognitif anak. Setelah semua proses dilalui maka dapat disimpulkan hasil penelitian tersebut. 
Penelitian dilakukan di Kelompok Bermain Miftahul Hidayah Desa Sidoharjo Kecamatan Guntur Kabupaten Demak. Subjek penelitian ini adalah 15 anak usia 3-4 tahun yang terdiri dari 9 anak laki-laki dan 6 anak perempuan yang belajar di Kelompok Bermain Miftahul Hidayah.

Teknik pengumpulan data yang digunakan adalah observasi (langsung dan tidak langsung) wawancara (terstruktur dan tidak terstruktur) dan dokumentasi. Tekni pengumpulan data ini dipergunakan peneliti kepada subjek penelitian guna menemukan data primer dan data skunder yang nantinya menjadi jawaban atas permasalahan yang muncul.

\section{HASIL DAN PEMBAHASAN}

Adapun tempat penelitian dilakukan di Kelompok Bermain Miftahul Hidayah - Demak. Kelompok Bermain Miftahul Hidayah merupakan lembaga yang terletak di Desa Sidoharjo Kecamatan Guntur Kabupaten Demak Provinsi Jawa Tengah. Kegiatan pembelajaran dilaksanakan setiap hari Senin s.d. Jum'at mulai pukul 07.00 WIB s.d. 10.00 WIB. Kelompok Bermain Miftahul Hidayah memiliki Visi "Terwujudnya anak usia dini yang cerdas, sehat, kreatif, mandiri serta berakhlakul karimah" dan menetapkan misi-misi terstruktus untuk menggapai visinya. Kelompok Bermain Miftahul Hidayah berdiri pada tahun 2013 yang di selenggarakan oleh pemerintah desa dan di kelola oleh bapak Ashari. Lembaga ini sudah terakreditasi C pada tahun 2019, karena belum memiliki gedung sendiri maka kegiatan belajar meminjam gedung TPQ.

Penelitian ini dilakukan ditengah pembelajaran luring dan daring dikarenakan pandemic Covid-19. Dalam proses pengambilan data anak-anak yang diteliti hadir bergantian sesuai pembagian kelompok dengan memberlakukan protocol Kesehatan. Adapun yang menjadi subjek penelitian adalah anak didik di kelompok Bermain Miftahul Hidayah Kabupaten Demak yang berjumlah 15 anak dengan rincian 9 anak laki - laki dan 6 anak perempuan.

Tabel 1. Daftar nama peserta didik

\begin{tabular}{|l|l|r|}
\hline No & \multicolumn{1}{|c|}{ Nama } & Umur \\
\hline 1 & Aditya Naufal Darry Abiyyu & 3,2 Tahun \\
\hline 2 & Ahmad Aufat Tamam & 4 Tahun \\
\hline 3 & Ahmad Mutamakkin & 3,9 Tahun \\
\hline 4 & Ahmad Raffi Ahnaf & 3 Tahun \\
\hline 5 & Anindita Keisha Zahra & 3 Tahun \\
\hline 6 & Aqila Fatimatuz Zahro & 3,7 Tahun \\
\hline 7 & Farihatul Ulya & 3 Tahun \\
\hline 8 & Himmatul Wafi Azzahra & 3 Tahun \\
\hline 9 & Muhammad Fitzal Asfa Muzakfar & 3,1 Tahun \\
\hline 10 & Muhammad Khoirul Khanafi & 3 Tahun \\
\hline 11 & Muhammad Syauqi Alfiyansyah & 3,1 Tahun \\
\hline 12 & Muhammad Khaidar & 3,4 Tahun \\
\hline 13 & Muhammad Wahyu Aji & 3,9 Tahun \\
\hline 14 & Riny Setyo Ningrum & 3,2 Tahun \\
\hline 15 & Sabrina Aulia Putri & 3,2 Tahun \\
\hline
\end{tabular}


Pada saat observasi dilakukan, terdapat banyak anak yang masih kebingungan untuk membedakan bentuk geometri, sehingga anak kurang antusias dalam mengikuti pembelajaran. ketersediaan media pembelajaran yang dapat menarik anak untuk belajar sangat terbatas, sehingga pembelajaran hanya menggunakan metode ceramah dan pemberian tugas.

Alasan pendidik saat peneliti melakukan wawancara yaitu kurangnya pengalaman dan kualifikasi pendidikan yang kurang di miliki pendidik sehingga pengajaran yang di berikan monoton dan kurang kreatif serta tuntutan orang tua yang meminta pendidik untuk mengajarkan anak-anak agar bisa menulis, membaca, dan menghitung. Hal ini membuat pendidik memilih mengajarkan kepada anak dengan gambar di papan tulis dan melakukan tanya jawab secara langsung ketika menjelaskan materi di papan tulis tersebut. Kemudian pada saat pendidik mengenalkan bentuk geometri pendidik menggunakan dua indikator pencapaian yaitu menyebutkan empat bentuk geometri (persegi, persegi panjang, segitiga, dan lingkaran) dan memasang bentuk geometri. Dalam penyampaian pengajarannya pendidik memilih untuk menggambarkan macam-macam bentuk geometri tersebut di papan tulis dan anak menyebutkan bentuk yang di gambarkan secara bersama. Selain itu pendidik menggunakan puzzle bentuk geometri dan menyusun beberapa balok yang ada di kelas, setelah itu dilanjutkan dengan mengerjakan lembar kerja siswa (LKS) yang ada dimajalah yang di sediakan sekolah.

Penelitian ini berawal dari serangkaian observasi pada proses pembelajaran mengenai kegiatan penelitian, dalam rangka meningkatkan kemampuan kognitif anak mengenal bentuk geometri dengan media permainan lompat geometri. Ditemukan bahwa anak-anak masih belum mampu dalam membedakan bentuk geometri, sehingga memberikan gambaran belum tercapainya tujuan pembelajaran. Hal ini berdasarkan hasil yang ditunjukkan pada saat peneliti bersama guru melakukan evaluasi pratindakan untuk mengetahui perkembangan awal kemampuan kognitif anak sebelum pelaksanaan kegiatan tindakan perbaikan pembelajaran dalam beberapa siklus tindakan. Dari hasil evaluasi pratindakan, diperoleh hasil secara klasikal dapat dideskripsikan kemampuan kognitif anak dalam mengenal bentuk geometri masih kurang. Dengan tingkat keberhasilan ketuntasan secara klasikal baru mencapai $40 \%$ sehingga perlu perbaikan pembelajaran di kelas. Data tersebut berdasarkan perolehan nilai akhir anak didik dalam kegiatan penilaian awal, setelah dianalisis dengan menggunakan perhitungan bobot nilai berdasarkan data temuan hasil evaluasi awal berupa nilai akhir masing-masing anak.

Gambar 1. Kegiatan Bermain Lompat Geometri

Ket: Anak melempar dadu

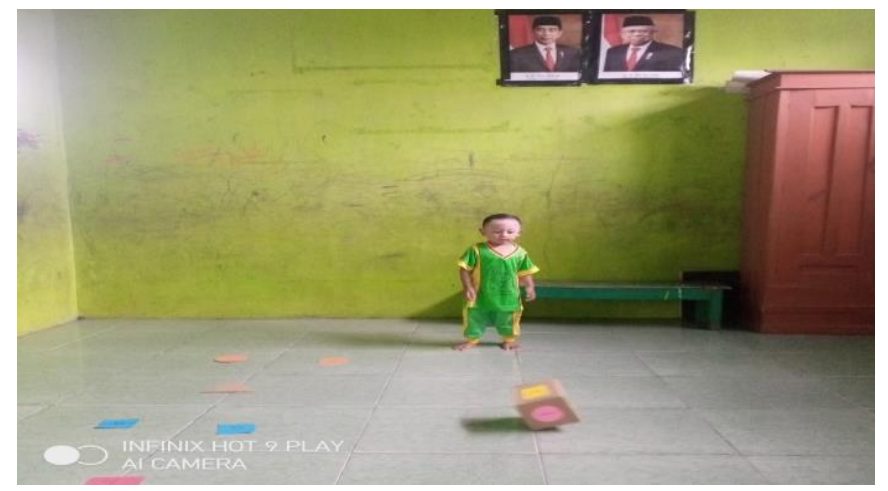


Gambar 2. Anak melompat dengan 1 kaki
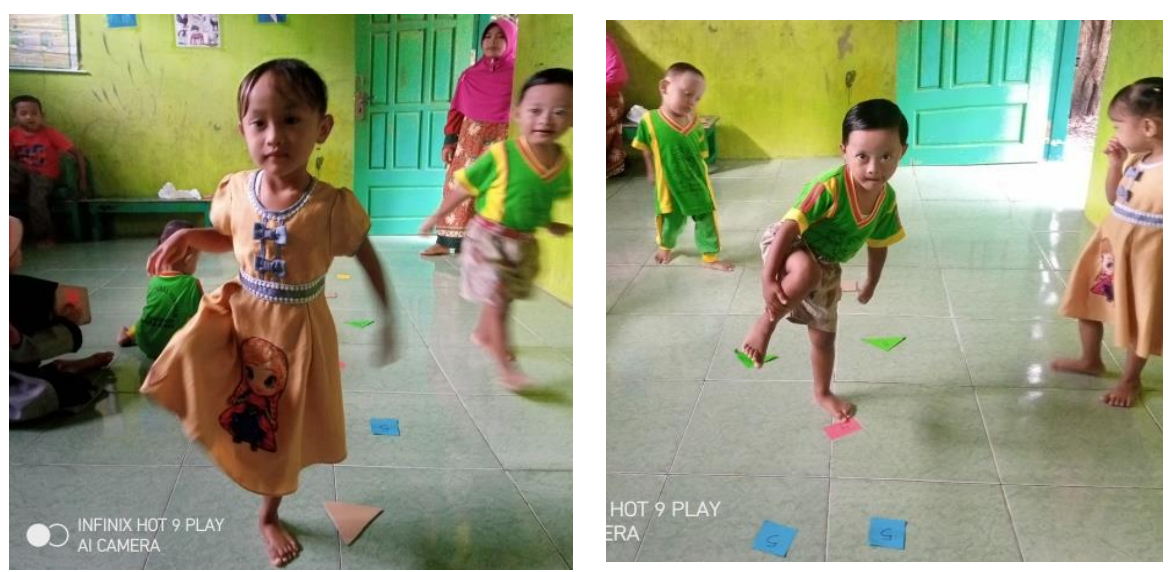

Ket: Anak melompat menuju ke bentuk Geometri sesuai dadu

Gambar 3. Anak melompat dengan dua kaki.
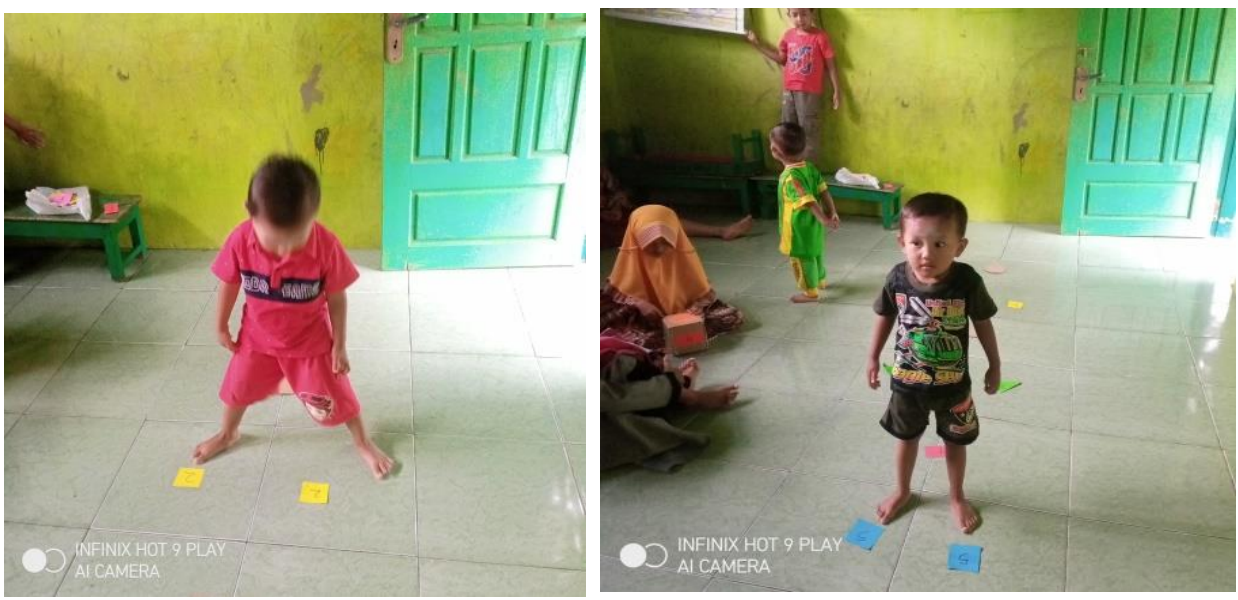

Ket: Anak melompat sesuai jumlah geometri yang di siapkan serta menyebutkan bentuk geometri tersebut

Pada penelitian ini masing-masing anak melakukan sesuai dengan aturan main dan kemudian gentian dengan temannya sesuai dengan jumlah anak yang diteliti. 
Tabel 2. Deskripsi Perolehan Nilai Ketuntasan Siklus I

\begin{tabular}{|l|c|l|l|}
\hline $\begin{array}{c}\text { Deskripsi Data Hasil } \\
\text { Evaluasi Tindakan Awal }\end{array}$ & $\begin{array}{c}\text { Frekuensi } \\
\text { (jumlah anak) }\end{array}$ & $\begin{array}{c}\text { Presentase } \\
\text { Siklus I }\end{array}$ & $\begin{array}{c}\text { Kriteria } \\
\text { Ketuntasan }\end{array}$ \\
\hline Berkembeng Sangat Baik (BSB) & 9 & $60 \%$ & Tuntas \\
\hline Berkembang Sesuai Harapan (BSH) & 6 & $40 \%$ & Belum Tuntas \\
\hline Mulai Berkembang (MB) & 0 & $0 \%$ & Belum Tuntas \\
\hline Belum Berkembang (BB) & 0 & 0 & Belum Tuntas \\
\hline Jumlah seluruh anak & 15 & $100 \%$ & \\
\hline $\begin{array}{l}\text { Persentase keberhasilan secara klasikal yakni jumlah } \\
\text { anak yang berhasil tuntas (BSB) }\end{array}$ & 9 & & \multicolumn{2}{|c|}{$40 \%$} \\
\hline $\begin{array}{l}\text { Jumlah persentase anak yang belum tuntas (MB } \\
\text { dan BB, dan BSH) }\end{array}$ & 60 & \\
\hline
\end{tabular}

Berdasarkan hasil pengamatan observasi dan evaluasi untuk menilai ketuntasan belajar anak dan melihat perubahan peningkatan kemampuan kognitif mengenal bentuk geometri pada anak di Kelompok Bermain Miftahul Hidayah. Bahwa hasil dari kegitatan evaluasi penilaian pada tahap siklus I secara klasikal yang berhasil tuntas sebanyak $60 \%$. Dengan demikian anak yang dipandang telah memiliki peningkatan kemampuan kognitif anak menggunakan media permainan lompat geometri sesuai dengan tahapan indikator. Sedangkan anak yang belum tuntas sebanyak $40 \%$. Hal ini menyebabkan pelaksanaaan tindakan belum mencapai kondisi yang optimal.

Tabel 3. Deskripsi Perolehan Nilai Ketuntasan Siklus II

\begin{tabular}{|l|c|c|l|}
\hline \multicolumn{1}{|c|}{ Deskripsi Data Hasil Evaluasi Siklus II } & $\begin{array}{c}\text { Frekuensi } \\
\text { (jumlah anak) }\end{array}$ & $\begin{array}{c}\text { Presentase } \\
\text { Siklus II }\end{array}$ & Kriteria Ketuntasan \\
\hline Berkembeng Sangat Baik (BSB) & 12 & $80 \%$ & Tuntas \\
\hline Berkembang Sesuai Harapan (BSH) & 3 & $20 \%$ & Belum Tuntas \\
\hline Mulai Berkembang (MB) & 0 & 0 & Belum Tuntas \\
\hline Belum Berkembang (BB) & 0 & 0 & Belum Tuntas \\
\hline Jumlah seluruh anak & 15 & $100 \%$ & $80 \%$ \\
\hline $\begin{array}{l}\text { Persentase keberhasilan secara klasikal yakni } \\
\text { jumlah anak yang berhasil tuntas (BSB) }\end{array}$ & 12 & \multicolumn{2}{|l}{$20 \%$} \\
\hline $\begin{array}{l}\text { Jumlah persentase anak yang belum tuntas } \\
\text { (MB dan BB, BSH) }\end{array}$ & 3 & & \\
\hline
\end{tabular}


Perolehan nilai dalam peningkatkan Meningkatkan Kemampuan Kognitif Anak dengan Permainan Lompat Geometri mengalami peningkatan dengan nilai yang dikategorikan tuntas, yakni sebanyak 12 anak didik atau sebesar $80 \%$. Hasil ini telah dipandang telah mampu menyelesaikan semua indikator-indikator dalam penelitian ini selama mengikuti kegiatan pembelajaran pada tindakan siklus II, meskipun masih ada anak didik yang memperoleh nilai kriteria belum tuntas sebanyak 3 orang anak didik atau sebesar $20 \%$.

Tabel 4. Deskripsi Perbandingan Nilai Ketuntasan Siklus I dan Siklus II

\begin{tabular}{|c|c|c|c|c|}
\hline $\begin{array}{c}\text { Deskripsi } \\
\text { Data Hasil Evaluasi }\end{array}$ & \multicolumn{2}{|c|}{$\begin{array}{c}\text { Hasil Evaluasi } \\
\text { Siklus I }\end{array}$} & \multicolumn{2}{|c|}{$\begin{array}{c}\text { Hasil Evaluasi } \\
\text { Siklus II }\end{array}$} \\
\hline 1 & 4 & 5 & 6 & 7 \\
\hline Berkembeng Sangat Baik (BSB) & 9 & $60 \%$ & 12 & $80 \%$ \\
\hline Berkembang Sesuai Harapan (BSH) & 6 & $40 \%$ & 3 & $20 \%$ \\
\hline Mulai Berkembang (MB) & 0 & $0 \%$ & 0 & $0 \%$ \\
\hline Belum Berkembang (BB) & 0 & $0 \%$ & 0 & $0 \%$ \\
\hline Jumlah seluruh anak & 15 & $100 \%$ & 15 & $100 \%$ \\
\hline Perolehan Secara Klasikal (Siklus I, Siklus II) & 9 & $60 \%$ & 12 & $80 \%$ \\
\hline
\end{tabular}

Grafik 1. Perbandingan Nilai Ketuntasan Siklus I dan Siklus II

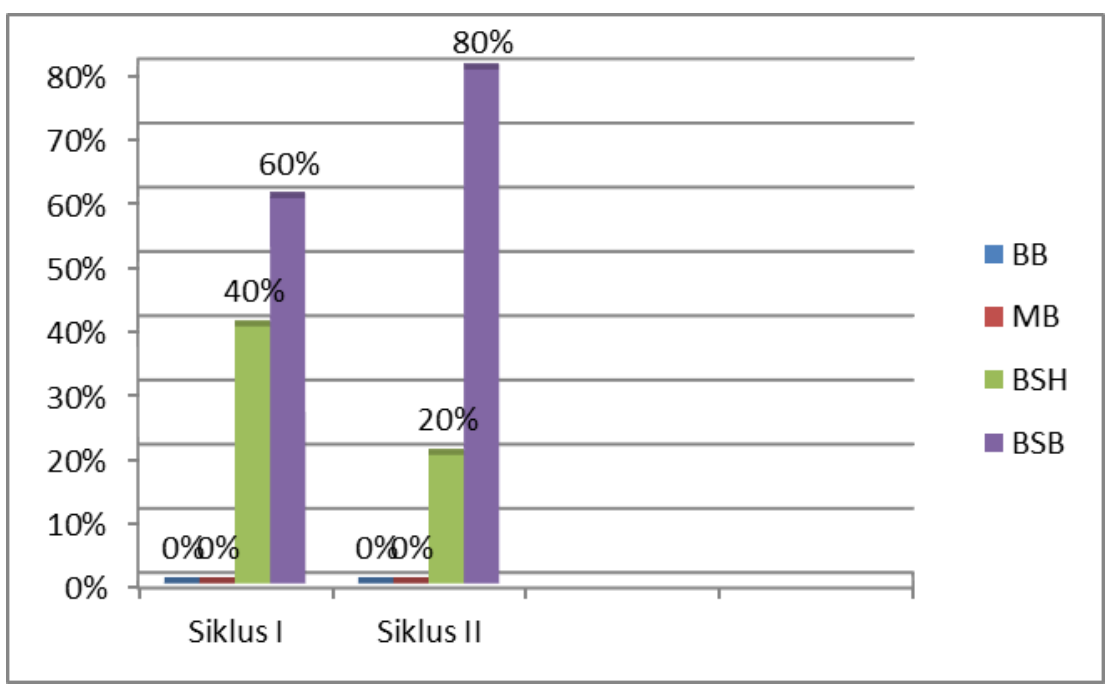

\section{SIMPULAN}

Kemampuan kognitif anak meningkat setelah melalui penerapan model pembelajaran yang dirangkum dalam metode bermain lompat geometri yang ditandai dengan tingginya pencapaian ketuntasan belajar pada masing-masing Siklus setelah menggunakan metode permainan lompat 
geometri. Penerapan metode bermain lompat geometri dalam meningkatkan kemampuan kognitif anak di Kelompok Bermain Miftahul Hidayah dilaksanakan berdasarkan dua siklus dimana masingmasing siklus peneliti didampingi dan dibantu oleh guru dalam pelaksanaannya, pelaksanaan pada masing-masing siklus kemudian diberikan penilaian terhadap perkembangan kemampuan kognitif anak.

\section{DAFTAR PUSTAKA}

Agustiningrum, M. D. B., Sayekti, S., Hardiyanti, D., Handayani, D. A. K., \& Redjeki, S. (2021). Tari Nawung Sekar: Kemampuan Sosial Anak Digital Natives di Era Revolusi Industri 4.0. Jurnal Obsesi: Jurnal Pendidikan Anak Usia Dini, 5(2), 1943-1950.

Afiyah, Z. (2017). Meningkatkan Kemampuan Fisik Motorik Anak Melalui Bhentik di TK Cempaka Mulya Sarimulya Kebonagung Demak. Semarang: Universitas Ivet.

Epstein, J. L. (2010). School, family, and community partnerships: Preparing educators and improving schools. Boulder, CO, USA: Westview Press.

Epstein, J. L. (2011). School, family, and community partnerships: Preparing educators and improving schools (2nd ed.). Philadelphia, PA: Westview Press.

Elyana, Luluk. "Manajemen Parenting Class Melalui Media E-Learning." Sentra Cendekia 1.1 (2020): 29-35.

Murgiyati, T., Agustiningrum, M. D. B., \& Anjarsari, I. (2020). Penggunaan Media APEMM SS BabeSeta dalam Pengenalan Konsep Dasar Matematika Awal pada Anak Usia 3-4 Tahun di KB Putra Champion Karangdowo Kecamatan Karangdowo Kabupaten Klaten. Sentra Cendekia, 1(2), 64-70.

Novitasari, Y. (2018). Analisis Permasalahan" Perkembangan Kognitif Anak Usia Dini”. PAUD Lectura: Jurnal Pendidikan Anak Usia Dini, 2(01), 82-90.

Slamet Suyanto. 2005. Konsep Dasar Pendidikan Anak Usia Dini. Jakarta: Departemen Pendidikan Nasional.

Sugiyono. (2013). Metode Penelitian Kuantitatif, Kualitatif dan R\&D. Bandung: Penerbit Alfabeta. 